\title{
Fortune 500 Listesinde Yer Alan Otomotiv Sektörü Firmalarının SWARA Destekli COPRAS Yöntemi İle Değerlendirilmesi
}

\author{
Eda ÇINAROĞLU \\ Erciyes Üniversitesi, Havacllık ve Uzay Bilimleri Fakültesi \\ Havacılık Yönetimi Bölümü \\ ecinaroglu@erciyes.edu.tr,ORCID:0000-0002-2904-3376
}

$\ddot{\mathbf{O z}}$

Sektörlere ait performans analizi geleceğe dönük öngörüler yapmak adına büyük önem arz etmektedir. $\mathrm{Bu}$ analiz farklı ölçek ve karaktere sahip çok sayıda ölçüt içerdiğinden klasik yöntemler yerine çok kriterli karar verme (ÇKKV) yöntemleri kullanılarak gerçekleştirilmektedir. Çalışmada otomotiv sektöründe faaliyet gösteren, Fortune 500 listesinde yer alan ve 2017 yılı net satış tutarı açısından ilk 10 sırayı teşkil eden firmaların performans sıralaması gerçekleştirilmiştir. $\mathrm{Bu}$ amaçla yapılan analizde kullanılan kriter ağırlıklarının belirlenmesi için SWARA yöntemi tercih edilmiş olup, bu kriter ağırlıkları esas alınarak COPRAS yöntemi ile firmaların performans sıralamasına ulaşılmıştır. Uygulama sonucunda en önemli değerlendirme kriterinin net satış, en yüksek performansa sahip firmanın ise Ford Otomotiv Sanayi A.Ş. olduğu tespit edilmiştir. Çalışmanın otomotiv sektörünün performansının yorumlanması ve isabetli kararlar alınması açısından işletme paydaşları için yol gösterici nitelik taşıması ümit edilmektedir.

Anahtar Kelimeler: Otomotiv sektörü, Performans Analizi, Çok Kriterli Karar Verme, COPRAS, SWARA.

JEL Sinıflandırma Kodları: C30, C44, M11.

\section{Evaluation of The Automotive Sector Companies in The Fortune 500 List with SWARA Supported COPRAS Method ${ }^{1}$}

\begin{abstract}
Sectoral performance analysis is of great importance to make forward-looking forecasts. Performance analysis for the sector is carried out by using multi-criteria decision making methods instead of classical methods since it contains many criteria with different scales and characters. In this study, the performance ranking of the automotive companies that are listed in the Fortune 500 list at the top 10 in terms of net sales amount in 2017, are performed. SWARA method is used to determine the criteria weights used in the analysis. Based on these criteria weights, the company's performance ranking has been achieved with the COPRAS method. As a result of the application, it is determined that the most important evaluation criteria is net sales amount and the firm with the highest performance is Ford Otomotiv Sanayi A.Ş. It is hoped that this study will guide the business stakeholders in terms of interpreting the performance of the automotive sector and making accurate decisions.
\end{abstract}

Keywords: Automotive sector, Performance Analysis, Multi Criteria Decision Making, COPRAS, SWARA.

JEL Classification Codes: C30, C44, M11.

\footnotetext{
${ }^{1}$ Extended abstract is presented at the end of the article.
}

Geliş Tarihi (Received): 02.04.2019 - Kabul Edilme Tarihi (Accepted): 30.12.2019

Atıfta bulunmak için/Cite this paper:

Çınaroğlu, E. (2019). Fortune 500 listesinde yer alan otomotiv sektörü firmalarının SWARA destekli COPRAS yöntemi ile değerlendirilmesi. Çankırı Karatekin Üniversitesi İ̈BF Dergisi, 9 (2), 593-611. 


\section{Giriş}

Karar verme insanoğlunun yaşamının her döneminde karşı karşıya olduğu bir olgudur. Düşünen bir beyne sahip olan insan tecrübe, bilgi birikimi ve ölçütleri esas alarak var olan seçenekler arasından en iyisini seçmeye çalışır. Günümüzün hızla değişen dinamik rekabet ortamı, maliyet baskısı ve teknolojik gelişmeler hem bireyleri, hem de işletmeleri en iyi kararları vermek konusunda zorlamaktadır. Karar verme süreci birbirleri ile çelişen çok sayıda kriter ve değerlendirmeye alınan çok sayıda alternatifin var olduğu durumlarda daha da karmaşık bir hal almaktadır. Rasyonel kararlar vermek için sadece sezgiler ve tecrübe birikimi yeterli olmayıp, analitik yaklaşımlara ihtiyaç duyulmaktadır. $\mathrm{Bu}$ bağlamda çok kriterli karar verme alanı her geçen gün yeni tekniklerin kazandırıldığı, hızlı bir ivme ile sürekli gelişen bir bilim dalı olarak önemini arttırmaktadır.

Çok Kriterli Karar Verme (ÇKKV) yöntemleri, birden çok kritere göre farklı özelliklere sahip alternatifler arasından en iyi olanın seçimi veya bu alternatiflerin belirlenen hedef doğrultusunda performanslarına göre sıralanması amacıyla kullanılmaktadır (Kaplanoğlu, 2018, s. 154). İşletmelerde performans değerlendirme süreci de pek çok ölçütün esas alındığ 1 bir karar verme problemi olup, çok kriterli karar verme tekniklerinin bu alanda kullanımı uygundur (Ömürbek ve Eren, 2016, s. 2).

Otomotiv sektörü ekonomimizin lokomotif sektörlerinden birisidir. Yüksek katma değer oranı, teknolojik gelişmeleri yakından izleyen yapısı, yatırımcılar için cezbedici özelliği ve dış ticaret rakamlarına olumlu etkisi ile Türkiye ekonomisinde önemli bir yer arz etmektedir. Otomotiv sanayii başta demir-çelik olmak üzere, akaryakıt, enerji, kimya, elektronik, yazılım, tekstil vb. sanayi dalları için ürün alıcısı konumunda olup; bu sektörlere de teknolojik gelişim ivmesini yansıtan ve katkı sağlayan bir sektördür. Ayrıca turizm, bakım-onarım, sigortacılık ve distribütörlük gibi çok sayıda hizmet sektörü için iş hacmi ve istihdam yaratılması anlamında büyük rol oynamaktadır. Bu bağlamda sektördeki her türlü değişim, ekonominin bütününü oldukça yakından ilgilendirmektedir (Yurdakul ve İç, 2003, s. 2).

Uludağ Otomotiv Endüstrisi İhracatçıları Birliği (OİB) verileri Türkiye otomotiv endüstrisinin ihracatta \%18'lik pay sahipliği ile lider konumda olduğunu işaret etmektedir. En yakın rakibi olan tekstil sektörünün ise ihracattaki pay1 \%11'dir. 2017 yılı itibariyle sektöre ait toplam ihracat rakamı 26 milyar ABD doları seviyesinde gerçekleşmiş olup, bu rakamın \%66'sını otomotiv ana sanayi ihracat rakamları teşkil etmektedir. 2016 yılı milli gelirinin \%4'ünü sağlayan ve sanayi üretiminde $\% 7^{\prime}$ lik bir pay sahibi olan otomotiv sektörü Türkiye'nin 10. Kalkınma Planı içerisinde stratejik öneme haiz bir sektör olarak yer almaktadır. Sektördeki firmaların gerek üretim, gerekse ihracat alanlarındaki başarılarını sürdürmeleri, teknolojik gelişmelere uyum sağlamaları ve yüksek performanslar ile etkin 
rekabet stratejileri uygulamaları bu bağlamda büyük önem taşımaktadır (Avcıoğlu vd, 2018, ss. 24-25).

Bu çalışmanın amacı, Fortune 500 Türkiye listesinde yer alan ve 2017 yılı net satış tutarı itibariyle ilk 10 sırayı teşkil eden otomotiv sektörü firmalarının performans analizini gerçekleştirmektir. $\mathrm{Bu}$ amaçla ÇKKV yaklaşımı esas alınarak SWARA destekli COPRAS yönteminin kullanımı tercih edilmiştir. Sektörde yer alan işletmelerin mevcut performansları hakkında bilgiye ulaşılması hem sektördeki konumlarının tespiti, hem de geleceğe yönelik rekabet stratejilerinin oluşturulması aşamalarında girişimciler, yatırımcılar ve şirket yöneticileri açısından önem arz etmektedir. Çalışmanın bu bağlamda katkı yaratacağı düşünülmektedir.

Çalışma beş bölümden oluşmaktadır. İkinci bölümde ÇÇKV tekniklerinden SWARA ve COPRAS yöntemleri ile ilgili literatür incelemesine yer verilmiştir. Üçüncü bölümde bu yöntemler detaylı olarak tanıtılmıştır. Dördüncü bölüm, önceki bölümlerde bahsedilen iki yöntemin performans değerlendirme problemine uygulamasını içermekte olup, bu bölümde ayrıca bulgulara yer verilmiştir. Beşinci bölümde ise sonuç ve öneriler yer almaktadır.

\section{Literatür Taraması}

Birden çok kriterin esas alındığı performans değerlendirme, karar alternatiflerini sıralama ve en iyiyi bulma problemlerinin çözümünde ÇKKV yöntemlerinin kullanımı son yıllarda büyük artış göstermiştir. Bu teknikler arasında yer alan COPRAS yöntemi ekonomik, finansal ve operasyonel performans değerlendirme amacıyla pek çok farklı alan ve sektöre yönelik çalışmada tercih edilmiştir.

Kaplanoğlu (2018), BİST'de işlem gören ve kimya imalat sanayinde faaliyet gösteren 32 şirketin 2016 yılına ait finansal performanslarının sıralanması amacıyla ARAS ve COPRAS yöntemlerini kullanmıştır. Çalışmada değerlendirme kriteri olarak nakit akış bilgilerine dayalı 18 oran yer almaktadır. Her iki yönteme ait siralamalarda ilk 10 ve son 10 şirketin benzerlik gösterdiği sonucuna ulaşılmıştır. İşletme faaliyetleri sonucunda pozitif yüksek nakit elde eden şirketlerin üst sıralarda yer aldığı belirlenmiştir.

Ömürbek ve Urmak Akçakaya (2018), Forbes 2000 listesinde yer alan havacıllk sektörü firmalarının değerlendirilmesinde Entropi destekli MAUT, COPRAS ve SAW yöntemlerini birlikte kullanmışlardır. 22 şirket için yapılan değerlendirmede yer alan kriterler satış, pazar değeri, aktif varlıklar ve çalışan sayısı kriterleridir. 3 farklı yöntem ile elde edilen sıralamaların bütünleştirilmesi ve son bir performans sıralaması oluşturulması amacıyla Borda Sayım yönteminden faydalanılmıştır.

Ömürbek, Aksoy ve Akçakanat (2017), aktif büyüklük esasına göre büyük ölçekteki bankaların sürdürülebilirlik performanslarının kıyaslanmasında Entropi 
destekli ARAS, COPRAS ve MOOSRA yöntemlerini kullanmışlardır. Performans analizi finansal (ekonomik), operasyonel (sosyal) ve çevresel başlıkları altında sınıflandırılan 3 ana kriter çerçevesinde gerçekleştirilmiştir.

Yavuz ve Öztel (2017) tarafindan yapılan çalışma, bilgi ve iletişim sektörü firmalarının COPRAS yöntemi ile finansal analizi konusunu içermektedir. 20102015 yılları arasındaki döneme ait 6 yıllık verinin kullanımı ile hesaplanan 10 adet finansal oran analizde değerlendirme kriteri olarak yer almıştır. Bu kriterlerin göreceli önem değerlerini belirlemek adına ağırlıklandırma yöntemi olarak Entropi yöntemi tercih edilmiştir. Çalışmanın amacı sektör firmalarının büyük, orta ve küçük ölçek sınıflamasına tabi tutulması ve her bir ölçek türü için yıllar bazında finansal başarı sıralamasının elde edilmesidir.

Uygurtürk ve Soylu (2016) tarafından yapılan çalışmada, BİST'de işlem gören 8 adet girişim sermayesi yatırım ortaklığının likidite ve karlılık performanslarının analizinde COPRAS yöntemi kullanılmıştır. 2013, 2014 ve 2015 yıllarını kapsayan analiz döneminde cari oran, nakit oran, özsermaye karlılı̆̆ karlılığı, aktif karlılığı, net kar marjı, satışların maliyeti oranı ve faaliyet giderleri oranı kriterleri esas alınmıştır.

Ömürbek ve Eren (2016) tarafindan yapılan araştırma PROMETHEE, MOORA ve COPRAS yöntemlerinin kullanımı ile gıda sektöründe yer alan bir firmanın 2005-2014 yıllarını içeren dönemdeki performansını 13 finansal oran çerçevesinde değerlendirmeyi amaçlamaktadır. Yıllara ait sıralama sonuçlarının üç yöntem için benzerlik içerdiği belirtilmiştir.

Aksoy, Ömürbek ve Karaatlı (2015), AHP temelli COPRAS yönteminin kullanımı ile Türkiye Kömür İşletmeleri’nin performans değerlendirmesini amaçlamışlardır. 2008-2012 dönemini içeren analizde dikkate alınan kriterler toplam satış, faaliyet karı, yatırım harcamaları, üretim miktarı, dekapaj miktarı, rezerv durumu ve çalışan sayısı kriterleridir.

Safaei Ghadikolaei, Khalıl Esbouei ve Antucheviciene (2014), Tahran Borsası'nda işlem gören 6 adet otomotiv firmasının finansal performansının ölçümünde bulanık ÇKKV tekniklerinin kullanımını tercih etmişlerdir. $\mathrm{Bu}$ teknikler arasında bulanık COPRAS yöntemi de yer almaktadır. Geleneksel muhasebe temelli finansal performans ölçütlerinin yer aldığ çalışmada modern değere dayalı finansal performans ölçütlerinden de yararlanılmıştır. Bulanık AHP analizi modern değere dayalı finansal performans ölçütlerinin geleneksel muhasebe temelli finansal performans ölçütlerinden daha büyük öneme sahip olduğu sonucunu içermektedir. Yöntemler 2002-2011 döneminde otomotiv firmaları için benzer sıralama sonuçlarına ulaşmıştır.

Esbouei ve Ghadikolaei (2013), çalışmalarında Tahran borsasında işlem gören otomobil yedek parçası üreticilerinin değerlendirilmesinde çok kriterli bir bakış 
açısını esas almışlardır. Çalışmada kriter ağırlıklarının belirlenmesi için bulanık analitik hiyerarşi süreci (FAHP) yaklaşımı uygulanmış olup, ardından şirketler COPRAS yöntemi kullanılarak finansal performanslarına göre sıralanmışlardır.

Ginevicius ve Podviezko (2013), Litvanya bankalarının finansal istikrarı ve sağlamlığının değerlendirilmesinde içlerinde COPRAS yönteminin de yer aldığı farklı ÇKKV tekniklerinden faydalanmışlardır. 2007-2009 yılları arasındaki dönemi içeren ve 8 ticari bankanın dahil edildiği analizde sermaye yeterliliği, yönetim yeterliliği, varlık kalitesi, kazanç düzeyi ve likidite olarak isimlendirilen 5 temel kategoriye ait 10 finansal oran esas alınmıştır.

Stanujkic vd. (2013), Sırbistan'da faaliyet gösteren 5 ticari bankanın sıralamasını yaptıkları çalışmalarında içlerinde COPRAS yönteminin de yer aldığı bazı ÇKKV yöntemlerini karşılaştırmalı olarak kullanmışlardır. 2011 yılı finansal raporlarından faydalanılan analizde likidite, verimlilik, karlılık ve sermaye yeterliliği kategorilerinde 13 alt kriter esas alınmıştır.

Das, Sarkar ve Ray (2012), çalışmalarında bulanık AHP ve COPRAS'tan oluşan entegre bir model kullanarak 7 Hint Teknoloji Enstitüsü'nün (IIT) paydaşların tercihine göre performans değerlendirmesi ve sıralamasına odaklanmışlardır.

SWARA yöntemi ÇKKV problemlerinde kriter ağırlıklarının belirlenmesi amacıyla sıklıkla tercih edilmektedir. $\mathrm{Bu}$ yöntemin kriter önem derecelerinin tespitine yönelik kullanımını içeren literatür araştırması örneklerine Tablo 1'de yer verilmiştir.

\section{Tablo 1: SWARA Yöntemi Literatür İncelemesi}

\begin{tabular}{|l|l|}
\hline Uygulama Alanı & \multicolumn{1}{|c|}{ Kaynakça } \\
\hline $\begin{array}{l}\text { İnşaat projesi } \\
\text { değerlendirmesi }\end{array}$ & Zolfani, Pourhossein, Yazdani, ve Zavadskas (2018). \\
\hline $\begin{array}{l}\text { Tablet markaları } \\
\text { değerlendirmesi }\end{array}$ & Can, Atalay ve Eraslan (2017). \\
\hline Personel seçimi & $\begin{array}{l}\text { Zolfani ve Banihashemi (2014); Karabašević, Stanujkić ve Urošević } \\
\text { (2015); Karabašević, Stanujkić, Urošević ve Maksimovic (2015); } \\
\text { Karabašević, Zavadskas., Turskis ve Stanujkic (2016); Stanujkic, } \\
\text { Djordjevic ve Karabašević (2015); Keršulienė ve Turskis (2011). }\end{array}$ \\
\hline Tedarikçi seçimi & $\begin{array}{l}\text { Alimardani, Hashemkhani Zolfani, Aghdaie ve Tamošaitienė (2013); } \\
\text { Aghdaie, Zolfani ve Zavadskas (2014); Yazdani, Hashemkhani Zolfani ve } \\
\text { Zavadskas (2016). }\end{array}$ \\
\hline Otel seçimi & Iş1k ve Adalı (2016). \\
\hline Makine seçimi & Çakır ve Sezen Akar (2017). \\
\hline
\end{tabular}

Literatür taraması sonucu otomotiv sektörünü içeren az sayıda performans sıralama çalışmasının var olduğu ve bu çalışmalarda genellikle finansal oranların esas alındığ 1 belirlenmiştir. Yapılan uygulamanın hem sektör, hem de kullanılan 
değerlendirme kriterleri açısından farklılık içerdiği ve literatüre katkı sağlayacağ 1 düşünülmektedir. SWARA ve COPRAS yöntemlerinin güncel veriler üzerinde entegre kullanımı ise çalışmanın diğer bir farklı yönü olarak ifade edilebilir.

\section{Yöntem}

Analizde kullanılan kriterlerin göreceli önem değerleri yani ağırlıklarının hesaplanmasında SWARA yöntemi esas alınmıştır. Karar alternatiflerinin karşılaştırılması ve performans sıralamalarının gerçekleştirilmesi için ise ÇKKV yöntemlerinden COPRAS yöntemi tercih edilmiştir.

\subsection{SWARA Yöntemi}

Son yıllarda gitgide daha sık kullanılan çok kriterli karar verme yöntemleri arasında yer alan SWARA (Step-wise Weight Assessment Ratio) yöntemi, ilk kez Keršuliene, Zavadskas ve Turskis (2010) tarafından ortaya konmuştur. "Adım Adım Ağırlık Değerlendirme Oran Analizi" olarak adlandırılan yöntem karar vericilere kendi önceliklerini belirleme hususunda firsat sunmaktadır. Karar verici statüsünde bulunan uzmanlar bu yöntemde önemli bir rol oynamaktadır. Uzmanlar tarafından yapılan değerlendirmede bilgi birikimi ve deneyimler esas alınmaktadır (Keršulienè, 2010, s. 250; Çakır ve Sezen Akar, 2017, s. 208).

SWARA yönteminde AHS yöntemine kıyasla gerekli karşılaştırma sayısı daha az olduğundan karar vericilerden daha tutarlı sonuçların elde edilmesi mümkün olmaktadır. Yine önceden tanımlanmış herhangi bir ölçeğe bağlı kalmaksızın kriterleri değerlendirme opsiyonu yöntemin ikinci avantajı olarak ifade edilebilir (Stanujkic, 2015, s. 182).

Yöntem uygulanırken ilk olarak karar vericiden analize dahil edilen değerlendirme kriterlerini önem sırasına göre azalan şekilde sıraya koyması istenir. Karar verici için en önemli olduğu düşünülen kriter ilk sırada, en az önemli olduğu düşünülen kriter ise son sırada olacak şekilde tüm kriterler sıralanır. Analize birden fazla karar vericinin dahil olması durumunda her bir karar verici için ayrı bir kriter sıralaması oluşturulur. Grup kararını içeren genel bir nihai sıralama elde edebilmek adına karar vericilerin kriter sıralamalarına ait geometrik ortalama değeri hesaplanır (Zolfani, Zavadskas ve Turskis, 2013, s. 158).

Kriterlerin azalan şekilde sıralanmasından sonra karar vericiye sıralamada yer alan her bir kriterin kendisinden sonra gelen kritere kıyasla ne ölçüde önemli olduğu sorulur. Bu mukayese sonrası gerekli parametreler hesaplanarak kriter ağırlık değerlerine ulaşılır. Analize birden fazla karar vericinin dahil olması durumunda karar verici sayısı kadar öncelik vektörü elde edilir. Bu durumda her bir kriter için öncelik vektörü değerinin geometrik ortalaması alınarak nihai öncelik değerlerine ulaş1lır (Özbek, 2017, s. 44). 
SWARA yöntemi uygulama süreci 5 adımdan oluşmaktadır. $\mathrm{Bu}$ adımlar şu şekildedir (Stanujkic vd., 2015, s. 55):

Adım 1: Kriterler karar verici görüşü esas alınarak önem düzeylerine göre azalan şekilde sıralanırlar.

Adım 2: İkinci kriterden başlayarak, karar verici her bir kriter için, önceki yani (j-1). kritere göre, kriter j'nin göreceli olarak azalan önemini ifade eder. Keršulienè vd. (2010), bu oranı $\mathrm{s}_{\mathrm{j}}$ ile göstermiş ve "ortalama değerin karşılaştırmalı önemi” olarak adlandırmışlardır.

Adım 3: $\mathrm{k}_{\mathrm{j}}$ katsayısı aşağıdaki gibi hesaplanır.

$k_{j}= \begin{cases}1, & j=1 \\ s_{j}+1, & j>1\end{cases}$

Adım 4: $\mathrm{q}_{\mathrm{j}}$ değişkeni aşağıdaki gibi hesaplanır.

$q_{j}=\left\{\begin{array}{rr}1, & j=1 \\ \frac{q_{j-1}}{k_{j}}, & j>1\end{array}\right.$

Adım 5: Değerlendirme kriterlerinin göreceli ağırlıkları (wj) şu şekilde hesaplanır.

$w_{j}=\frac{q_{j}}{\sum_{k=1}^{n} q_{k}}$

\subsection{COPRAS Yöntemi}

"Karmaşık Oransal Değerlendirme" anlamı taşıyan COPRAS (Complex Proportional Assessment) yöntemi 1996 yılında Vilnius Gediminas Teknik Üniversitesi akademisyenlerinden Zavadskas ve Kaklauskas tarafından geliştirilmiştir. Yöntem alternatifleri birbirleri ile kıyaslayarak ne kadar iyi veya ne kadar kötü olduklarını belirlemektedir (Kaplanoğlu, 2018, s. 179). Değerlendirme sürecinde fayda kriterlerinin en üst düzeye çıkartılması, faydasız kriterlerin ise en alt düzeye indirgenmesi hedeflenmektedir. COPRAS hem kalitatif, hem de kantitatif ölçütlerin değerlendirilmesini mümkün kılan, kullanımı kolay, işlem süreci kısa ve hesaplama adımları kolay bir ÇKKV tekniğidir. Diğer bazı ÇKKV yöntemlerinin kullanımı esnasında enazlanması hedeflenen ölçüt değerleri için ihtiyaç duyulan zaman alıcı dönüşüm işlemini gerektirmemesi üstün bir yönü olarak ifade edilebilir (Mulliner, Smallbone ve Maliene, 2013, s. 274).

COPRAS yöntemine ait işlem adımları şu şekilde sıralanabilir (Zavadskas, Kaklauskas, Banaitis ve Kvederyte, 2004, s. 349):

Adım 1: Karar matrisinin oluşturulması

Karar matrisine ait her $x_{i j}$ elemanı için $i$ karar alternatiflerini $(i=1,2, \ldots . m), j$ ise kriterleri $(j=1,2 \ldots ., n)$ ifade etmektedir. 
$X_{i j}=\left[\begin{array}{cccc}x_{11} & x_{12} & \cdots & x_{1 n} \\ x_{21} & x_{22} & \cdots & x_{2 n} \\ \vdots & \vdots & \ddots & \vdots \\ x_{m 1} & x_{m 2} & \cdots & x_{m n}\end{array}\right]$

Adım 2: Ağırlıklı standardize edilmiş karar matrisinin oluşturulması

$d_{i j}=\frac{x_{i j} q_{j}}{\sum_{i=1}^{m} x_{i j}}, i=\overline{1, m} j=\overline{1, n}$

Formülde yer alan $q_{i}$ değeri kriter ağırlıklarını göstermektedir.

$q_{j}=\sum_{i=1}^{m} d_{i j}, \quad i=\overline{1, m} j=\overline{1, n}$

Adım 3: Ağırlıklı normalize indekslerin toplanması

$S_{+i}=\sum_{j=1}^{n} d_{+i j} ; S_{-i}=\sum_{j=1}^{n} d_{-i j}, i=\overline{1, m} j=\overline{1, n}$

Adım 4: Alternatiflerin göreceli öneminin hesaplanması

$Q_{i=} S_{+i}+\frac{S_{-\min } \sum_{i=1}^{m} S_{-i}}{S_{-i} \sum_{i=1}^{m} \frac{S_{-\min }}{S_{-i}}} i=\overline{1, m} j=\overline{1, n}$

Adım 5: Alternatiflerin fayda derecesinin belirlenmesi

$N_{i}=\frac{Q_{i}}{Q_{\max }} * 100 \%$

\section{Uygulama}

Fortune Dergisi dünyanın 120 ülkesinde 5 milyonun üzerinde okuyucu kitlesine sahip olan iş dünyası dergisidir. Fortune Türkiye ise 2007 y1lı itibariyle yayınlanmaya başlamış olup, "Türkiye'nin en büyük 500 şirketi”, "Türkiye'nin en güçlü kadınları", "Yılın iş insanı", "Türkiye'nin en beğenilen şirketleri” vb. farklı başarı listeleri ile ün kazanmıştır (www.fortuneturkey.com).

Çalışmada otomotiv sektöründe faaliyet gösteren Fortune 500 listesinde yer alan ve 2017 yılı net satış tutarı açısından ilk 10 sırayı teşkil eden firmaların performans ölçümü amaçlanmıştır. Analize konu edinilen firmalar listede "taşıt araçları ve ekipmanları imalat ve bakımı" ile "motorlu taşıt satış ve servisi" alt sektör başlıkları içerisinde gruplandırılmış olanlardır. Firmalar 8 kriter açısından değerlendirilmiştir. Çok kriterli karar verme tekniklerinden SWARA yöntemi ile kriter ağırlıkları belirlenmiş ve bu ağırlıklar esas alınarak COPRAS yöntemi ile performans sıralamaları oluşturulmuştur. Kullanılan değerlendirme kriterleri literatür taraması sonucunda performans analizi ile ilgili farklı çalışmalardan 
yararlanılarak belirlenmiş ve kodları ile birlikte Tablo 2'de sunulmuştur (Çakır ve Perçin, 2013; Başdeğirmen ve Tunca, 2017, Başdeğirmen ve Iş1ldak, 2018; Özbek, 2018; Özbek ve Demirkol, 2018).

Değerlendirme kapsamına alınan 10 firma ve kodları ise Tablo 3'de yer almaktadır.

Tablo 2: Değerlendirmede Kullanılan Kriterler ve Kodları

\begin{tabular}{|c|c|}
\hline KOD & KRİTER \\
\hline K1 & Net Satış \\
\hline K2 & Net Satış Değişimi \\
\hline K3 & Faiz, Vergi Öncesi Kar \\
\hline K4 & Faiz, Vergi Öncesi Kar Değişimi \\
\hline K5 & Aktif Toplam \\
\hline K6 & Özkaynak \\
\hline K7 & İhracat \\
\hline K8 & Çalışan Sayısı \\
\hline
\end{tabular}

Tablo 3: Değerlendirme Kapsamında Yer Alan Firmalar ve Kodları

\begin{tabular}{|c|l|}
\hline KOD & \multicolumn{1}{c|}{ FİRMA } \\
\hline F1 & Ford Otomotiv Sanayi A.Ş. \\
\hline F2 & Doğuş Otomotiv Servis ve Ticaret A.Ş. \\
\hline F3 & Otokoç Otomotiv Ticaret ve Sanayi A.Ş. \\
\hline F4 & Borusan Otomotiv İthalat ve Dağıtım A.Ş. \\
\hline F5 & Abdülkadir Özcan Otomotiv Lastik San. ve Tic. A.Ş. \\
\hline F6 & Otokar Otomotiv ve Savunma Sanayi A.Ş. \\
\hline F7 & Avek Otomotiv Servis Sanayi ve Ticaret A.Ş. \\
\hline F8 & Has Otomotiv Yatırım ve Pazarlama A.Ş. \\
\hline F9 & Anadolu Isuzu Otomotiv Sanayi ve Ticaret A.Ş. \\
\hline F10 & Karsan Otomotiv Sanayii ve Ticaret A.Ş. \\
\hline
\end{tabular}

\subsection{SWARA Yöntemi ile Kriter Ağırlıklarının Belirlenmesi}

Analiz sürecinde öncelikle Tablo 2'de yer alan değerlendirme kriterlerine ait ağırlıkların tespiti için 5 adımlık SWARA yöntemi uygulanmıştır. Bu adımlar ve her aşamada elde edilen bulgular aşağıdaki gibidir.

Adım 1 ve Adım 2: Bu aşamada 3 finans uzmanından kriterlerin en önemliden en az önemliye doğru sıralanması istenmiştir. Bu şekilde 3 farklı önem sıralaması 
elde edilmiştir. Sonrasında sıralamayı gerçekleştiren her bir uzman, her kriterin kendisinden sonra sıralamada yer alan kriterden görece olarak ne düzeyde önemli olduğunu belirtmiştir. Ortalama değerin karşılaştırmalı önemi olarak adlandırılan bu oranlar $\mathrm{s}_{\mathrm{j}}$ ile gösterilmiştir. Karar vericilerin kriter sıralamaları ve bu kriterlerin karşılaştırmalı önem değerleri Tablo 4'de yer almaktadır. Örneğin karar verici 1 (KV1) için en önemli kriterin K1(Net Satış) kriteri olduğu ve aynı karar verici için K1 (Net Satış) ile K6 (Özkaynak) kriterleri arasındaki karşılaştırmalı önem değerinin 0.10 olduğu görülmektedir.

Tablo 4: Kriterler Sıralamaları ve Karşılaştırmalı Önem Değerleri

\begin{tabular}{|c|c|c|c|c|c|c|}
\hline & \multicolumn{2}{|c|}{ KV1 } & \multicolumn{2}{c|}{ KV2 } & \multicolumn{2}{c|}{ KV3 } \\
\hline $\begin{array}{c}\text { ÖNEM } \\
\text { SIRASI }\end{array}$ & KRITER & $\boldsymbol{s}_{\boldsymbol{i}}$ & KRiTER & $\boldsymbol{s}_{\boldsymbol{j}}$ & KRITER & $\boldsymbol{S}_{\boldsymbol{j}}$ \\
\hline $\mathbf{1}$ & $\mathrm{K} 1$ & & $\mathrm{~K} 1$ & & $\mathrm{~K} 1$ & \\
\hline $\mathbf{2}$ & $\mathrm{K} 6$ & 0.100 & $\mathrm{~K} 6$ & 0.100 & $\mathrm{~K} 6$ & 0.100 \\
\hline $\mathbf{3}$ & $\mathrm{K} 3$ & 0.050 & $\mathrm{~K} 3$ & 0.100 & $\mathrm{~K} 3$ & 0.150 \\
\hline $\mathbf{4}$ & $\mathrm{K} 7$ & 0.250 & $\mathrm{~K} 2$ & 0.050 & $\mathrm{~K} 7$ & 0.100 \\
\hline $\mathbf{5}$ & $\mathrm{K} 5$ & 0.400 & $\mathrm{~K} 4$ & 0.050 & $\mathrm{~K} 5$ & 0.100 \\
\hline $\mathbf{6}$ & $\mathrm{K} 4$ & 0.150 & $\mathrm{~K} 5$ & 0.100 & $\mathrm{~K} 4$ & 0.050 \\
\hline $\mathbf{7}$ & $\mathrm{K} 2$ & 0.200 & $\mathrm{~K} 7$ & 0.200 & $\mathrm{~K} 2$ & 0.200 \\
\hline $\mathbf{8}$ & $\mathrm{K} 8$ & 0.200 & $\mathrm{~K} 8$ & 0.200 & $\mathrm{~K} 8$ & 0.200 \\
\hline
\end{tabular}

Adım 3, Adım 4 ve Adım 5: Bu aşamada öncelikle Eşitlik 1 esas alınarak $s_{j}{ }^{\prime}$ ler yardımıyla $\mathrm{k}_{\mathrm{j}}$ katsayıları hesaplanmıştır. Bu katsayılar kullanılarak Eşitlik 2 ile $q_{j}$ değişkenlerine ulaşılmıştır. Değerlendirme kriterlerinin göreceli ağırlıkları wj' ler ise Eşitlik 3 yardımıyla belirlenmiştir. Karar verici 1 (KV1)'e ait her bir kriter için hesaplanan $k_{j}, q_{j}$ ve $w_{j}$ değerleri Tablo 5'de yer almaktadır.

Tablo 5: Karar Verici 1'e Ait Kriter Ağırlıklarını Hesaplama

\begin{tabular}{|c|c|l|l|l|l|}
\hline ÖNEM SIRASI & KRITER & $\boldsymbol{S}_{\boldsymbol{j}}$ & $\boldsymbol{k}_{\boldsymbol{j}}$ & \multicolumn{1}{|c|}{$\boldsymbol{q}_{\boldsymbol{j}}$} & $\boldsymbol{w}_{\boldsymbol{j}}$ \\
\hline $\mathbf{1}$ & $\mathrm{K} 1$ & & 1.000 & 1.000 & 0.198 \\
\hline $\mathbf{2}$ & $\mathrm{K} 6$ & 0.100 & 1.100 & 0.909 & 0.180 \\
\hline $\mathbf{3}$ & $\mathrm{K} 3$ & 0.050 & 1.050 & 0.866 & 0.171 \\
\hline $\mathbf{4}$ & $\mathrm{K} 7$ & 0.250 & 1.250 & 0.693 & 0.137 \\
\hline $\mathbf{5}$ & $\mathrm{K} 5$ & 0.400 & 1.400 & 0.495 & 0.098 \\
\hline $\mathbf{6}$ & $\mathrm{K} 4$ & 0.150 & 1.150 & 0.430 & 0.085 \\
\hline $\mathbf{7}$ & $\mathrm{K} 2$ & 0.200 & 1.200 & 0.359 & 0.071 \\
\hline $\mathbf{8}$ & $\mathrm{K} 8$ & 0.200 & 1.200 & 0.299 & 0.059 \\
\hline
\end{tabular}

Tablo 5'de karar verici 1 için gerçekleştirilen hesaplamaların diğer karar vericiler için de yapılması sonucu elde edilen kriter ağırlıkları Tablo 6'ya aktarılmıştır. Yine aynı tabloda her bir karar vericiye ait kriter ağırlıklarının geometrik ortalaması alınarak normalize edilmesi sonucu elde edilen nihai kriter ağırlıkları da yer almaktadır. Değerlendirme sonucunda, en önemli kriterin 0.182 değeriyle 
K1 (Net Satış) kriteri olduğu sonucuna ulaşılmıştır. En az önem arz eden kriter ise 0.072 değerine sahip olan K8 (Çalışan Sayısı) kriteri olmuştur.

Tablo 6: Kriterlerin KV'ler Bazında ve Nihai Olarak Hesaplanan Ağırlıkları

\begin{tabular}{|c|l|r|r|r|r|}
\hline KRITER & $\begin{array}{l}\text { KRITER } \\
\text { AÇIKLAMASI }\end{array}$ & $\begin{array}{c}\text { KV1 } \\
\text { için } \\
\text { ağırlık }\end{array}$ & $\begin{array}{c}\text { KV2 için } \\
\text { ağırlık }\end{array}$ & $\begin{array}{c}\text { KV3 için } \\
\text { ağırlık }\end{array}$ & $\begin{array}{c}\text { Nihai } \\
\text { Ăğırlık }\end{array}$ \\
\hline K1 & Net Satış & 0.198 & 0.167 & 0.177 & 0.182 \\
\hline K2 & Net Satış değişimi & 0.071 & 0.131 & 0.092 & 0.096 \\
\hline K3 & FVÖK & 0.171 & 0.138 & 0.14 & 0.150 \\
\hline K4 & FVÖK değişim & 0.085 & 0.125 & 0.11 & 0.106 \\
\hline K5 & Aktif Toplam & 0.098 & 0.114 & 0.116 & 0.110 \\
\hline K6 & Özkaynak & 0.18 & 0.152 & 0.161 & 0.165 \\
\hline K7 & İhracat & 0.137 & 0.095 & 0.127 & 0.119 \\
\hline K8 & Çalışan Sayısı & 0.059 & 0.079 & 0.077 & 0.072 \\
\hline
\end{tabular}

4.2. COPRAS Yöntemi ile Performans Sıralamasının Belirlenmesi

SWARA yöntemi ile ulaşılan kriter ağırlıklarının COPRAS yönteminde kullanımı ile firmalara ait performans sıralamasına ulaşılmıştır. Bu adımlar şu şekildedir: Adım1: Karar matrisinin oluşturulması: Kullanılan 8 kriter ve analize dahil edilen 10 firma esas alınarak oluşturulan $(10 * 8)$ boyutlu karar matrisi Tablo 7'dedir.

Tablo 7: Karar Matrisi

\begin{tabular}{|c|c|c|c|c|c|c|c|c|}
\hline & K1 & $\mathbf{K} 2$ & K3 & K4 & K5 & K6 & K7 & K8 \\
\hline F1 & 25.341 .290 .000 & 38.559 & 2.267.392.000 & 60.198 & 12.011 .740 .000 & 3.695 .859 .000 & 17.830 .091 .000 & 1508 \\
\hline F2 & 13.220 .361 .000 & 10.861 & 575.288 .000 & 5.012 & 5.166 .882 .000 & 1.327 .445 .000 & 0 & 2781 \\
\hline F3 & 6.346 .364 .000 & 34.185 & 563.235 .000 & 52.413 & 4.216 .900 .000 & 592.798 .000 & 0 & 2387 \\
\hline F4 & 2.879 .382 .000 & -4.189 & 73.221 .000 & 47.775 & 1.161 .228 .000 & 151.094 .000 & 1.692 .000 & 253 \\
\hline F5 & 1.789 .062 .746 & 26.130 & 232.789 .407 & 38.239 & 2.832 .520 .584 & 1.401 .747 .004 & 639.806 .580 & 1100 \\
\hline F6 & 1.785 .272 .000 & 9.223 & 241.512 .000 & 33.989 & 2.009.587.000 & 283.554 .000 & 552.285 .000 & 2147 \\
\hline F7 & 1.467 .284 .824 & 22.475 & 39.987 .235 & -8.817 & 529.400 .167 & 105.957.569 & 0 & 602 \\
\hline F8 & 1.023 .579 .929 & 25.704 & 24.258 .626 & 43.105 & 457.823 .735 & 65.108 .846 & 12.270 .984 & 299 \\
\hline F9 & 963.126 .462 & 16.066 & 37.314 .181 & 124.787 & 1.453 .483 .993 & 628.126 .018 & 230.532 .668 & 875 \\
\hline F10 & 953.186 .497 & 19.598 & 173.729 .936 & 86.893 & 1.826 .045 .346 & 355.004 .434 & 407.019 .801 & 947 \\
\hline
\end{tabular}

Adım 2: Ăgırlıklı standardize edilmiş karar matrisinin oluşturulması: Karar matrisinin normalize edilerek her bir sütunun SWARA yöntemi ile elde edilmiş olan kriter ağırlıkları $\left(w_{i}\right)$ ile çarpılması sonucu oluşturulan ağırlıklı standardize edilmiş karar matrisi Tablo 8'de yer almaktadır. 
Tablo 8: Ağırlıklı Standardize Edilmiş Karar Matrisi

\begin{tabular}{|c|c|c|c|c|c|c|c|c|}
\hline & K1 (+) & K2 (+) & K3 (+) & K4 (+) & K5 (+) & K6 (+) & K7 (+) & K8 (-) \\
\hline F1 & 0.083 & 0.019 & 0.080 & 0.013 & 0.042 & 0.071 & 0.108 & 0.008 \\
\hline F2 & 0.043 & 0.005 & 0.020 & 0.001 & 0.018 & 0.025 & 0.000 & 0.016 \\
\hline F3 & 0.021 & \begin{tabular}{|l|}
0.017 \\
\end{tabular} & 0.020 & 0.011 & 0.015 & 0.011 & 0.000 & 0.013 \\
\hline F4 & 0.009 & -0.002 & 0.003 & 0.010 & 0.004 & 0.003 & 0.000 & 0.001 \\
\hline F5 & 0.006 & 0.013 & 0.008 & 0.008 & 0.010 & 0.027 & 0.004 & 0.006 \\
\hline F6 & 0.006 & 0.004 & 0.009 & 0.007 & 0.007 & 0.005 & 0.003 & 0.012 \\
\hline F7 & 0.005 & 0.011 & 0.001 & -0.002 & 0.002 & 0.002 & 0.000 & 0.003 \\
\hline F8 & 0.003 & 0.012 & 0.001 & 0.009 & 0.002 & 0.001 & 0.000 & 0.002 \\
\hline F9 & 0.003 & 0.008 & 0.001 & 0.027 & 0.005 & 0.012 & 0.001 & 0.005 \\
\hline F10 & 0.003 & 0.009 & 0.006 & 0.019 & 0.006 & 0.007 & 0.002 & 0.005 \\
\hline
\end{tabular}

Adım 3, Adım 4 ve Adım 5: Ağırlıkl normalize indekslerin toplanması, alternatiflerin göreceli öneminin hesaplanmass ve fayda derecelerinin belirlenmesi: Faydalı ölçütler için $S_{+i}$, faydasız ölçütler için ise $S_{-i}$ indeks değerleri Eşitlik 7 yardımı ile hesaplanmıştır. $\mathrm{Bu}$ indeks değerlerinin yardımıyla alternatiflerin göreceli önem değerlerinin (Qi) belirlenmesinde Eşitlik 8 kullanılmıştır. Eşitlik 9 esas alınarak alternatiflerin fayda dereceleri $\left(N_{i}\right)$ belirlenmiş ve bu değerlerin büyükten küçüğe sıralanması ile firma performans sıralamalarına ulaşılmıştır. Tüm bu sonuçlara Tablo 9'da yer verilmiştir.

Tablo 9: $S_{+i}, S_{-i}, Q_{i}, N_{i}$ değerleri ve firma sıralamaları

\begin{tabular}{|l|c|c|c|c|c|}
\hline & $\boldsymbol{S}_{+\boldsymbol{i}}$ & $\boldsymbol{S}_{\boldsymbol{i}}$ & $\boldsymbol{Q}_{\boldsymbol{i}}$ & $\boldsymbol{N}_{\boldsymbol{i}}$ & Siralama \\
\hline F1 & 0.415 & 0.015 & 0.421 & 1.000 & 1 \\
\hline F2 & 0.113 & 0.027 & 0.117 & 0.277 & 2 \\
\hline F3 & 0.095 & 0.023 & 0.098 & 0.234 & 3 \\
\hline F4 & 0.027 & 0.002 & 0.063 & 0.149 & 7 \\
\hline F5 & 0.076 & 0.011 & 0.084 & 0.199 & 4 \\
\hline F6 & 0.042 & 0.021 & 0.046 & 0.110 & 9 \\
\hline F7 & 0.019 & 0.006 & 0.034 & 0.080 & 10 \\
\hline F8 & 0.029 & 0.003 & 0.059 & 0.140 & 8 \\
\hline F9 & 0.058 & 0.008 & 0.068 & 0.162 & 5 \\
\hline F10 & 0.053 & 0.009 & 0.063 & 0.149 & 6 \\
\hline
\end{tabular}

\section{Sonuç ve Öneriler}

Globalleşme firmalar arasındaki rekabeti hızla arttırmaktadır. Dinamik rekabet ortamında firmaların hayatta kalabilmesi ve süreklilik arz etmesi performans sonuçları ile yakından ilişkilidir. Bu bağlamda firmaların performanslarının tespiti gerek sektör içerisindeki konumlarının belirlenmesi, gerekse geleceğe yönelik stratejilerinin oluşturulmasında gösterge niteliği taşımaktadır. Bu değerlendirme hem şirket yöneticileri, hem girişimciler, hem yatırımcılar, hem de ekonomi yönetimi açısından büyük önem arz etmektedir. 
$\mathrm{Bu}$ çalışmada otomotiv sektöründe faaliyet gösteren, FORTUNE 500 listesinde yer alan ve 2017 yılı net satış tutarı açısından ilk 10 sırayı teşkil eden firmaların performansa göre sıralaması gerçekleştirilmiştir. Değerlendirmede esas alınan kriterler net satış, net satış değişimi, faiz vergi öncesi kar, faiz vergi öncesi kar değişimi, aktif toplamı, özkaynak, ihracat ve çalışan sayısı kriterleridir. Çalışmada ÇKKV yöntemlerinden SWARA ve COPRAS yöntemleri bütünleşik olarak kullanılmıştır. Analize dahil edilen kriterlerin ağırlıklarının belirlenmesinde SWARA yöntemi tercih edilmiş olup, bu kriter ağırlıkları esas alınarak COPRAS yöntemi ile firmaların performans sıralamasına ulaşılmıştır. Uygulama ile en önemli değerlendirme kriterinin net satış (K1) olduğu belirlenmiştir. Diğer kriterler içerisinde özkaynak ve faiz vergi öncesi kar kriterlerinin de performans değerlendirme açısından oldukça etkili olduğu saptanmıştır. İlgili dönemde en iyi performansa sahip firmanın Ford Otomotiv Sanayi A.Ş. (F1) olduğu tespit edilmiştir. İkinci sırada yer alan firma Doğuş Otomotiv Servis ve Ticaret A.Ş. (F2) iken, üçüncü sıradaki firma Otokoç Otomotiv Ticaret ve Sanayi A.Ş. (F3) olmuştur. $\mathrm{Bu}$ siralama FORTUNE 500 listesi siralaması ile tutarlılık göstermektedir. Son sırada yer alan, yani ilgili dönemde en düşük performans gösteren firma ise Avek Otomotiv Servis Sanayi ve Ticaret A.Ş. (F7)'dir.

Çalışmanın ana motivasyonu otomotiv sektörünün performansının yorumlanması ve isabetli kararlar alınması açısından işletme paydaşlarıne yol gösterici nitelik taşımasıdır. Gerçekleştirilen performans sıralaması sonucunda üst sıralarda yer alan firmalar yatırımcılar açısından önerilebilir nitelik taşımaktadır. Son sıralarda yer alan firmalara ise başarılı rakiplerini esas alarak üstün ve zayıf yönlerini tespit etmeleri ve net satış, özkaynak ve faiz vergi öncesi kar kriterlerine odaklanarak rekabet stratejilerini yeniden biçimlendirmeleri önerilebilir.

Uygulamada esas alınan kriterlerde değişiklik yapılması ya da farklı bir dönemin dikkate alınması durumunda değerlendirme kapsamındaki firmaların performans sıralamasında değişiklik olabileceği göz önünde bulundurulmalıdır. Ayrıca SWARA ve COPRAS yöntemleri haricindeki ÇKKV tekniklerinin kullanımı da analiz sonuçlarında farklılıkları beraberinde getirebilecektir. İlerleyen çalışmalarda farklı sektörleri kapsamına alan performans ölçümü uygulamaları yapılarak sektörel bazda önem arz eden ölçütlerin benzerliği kıyaslanabilir. Ya da farklı ÇKKV tekniklerinin kullanımı ile elde edilecek sıralamalar karşılaştırılabilir. 


\section{Kaynakça}

Aghdaie, M. H., Zolfani, S. H. ve Zavadskas, E. K. (2014). Synergies of data mining and multiple attribute decision making. Procedia-Social and Behavioral Sciences, 110, 767-776.

Alimardani, M., Hashemkhani Zolfani, S., Aghdaie, M. H. ve Tamošaitienė, J. (2013). A novel hybrid SWARA and VIKOR methodology for supplier selection in an agile environment. Technological and Economic Development of Economy, 19(3), 533-548.

Aksoy, E., Ömürbek, N. ve Karaatlı, M. (2015). AHP Temelli MULTIMOORA ve COPRAS yöntemi ile Türkiye Kömür İșletmeleri'nin performans değerlendirmesi. Hacettepe Üniversitesi Iktisadi ve Idari Bilimler Fakültesi Dergisi, 33(4), 1-28.

Avcıoğlu, C., Urhan, C., Özçelik, D., Eryılmaz, E., Özgüner, İ., Mermertaş, Ş. ve diğer. (2018). Sektörel görünüm: Otomotiv ana ve yan sanayi. http://www.tskb.com.tr/i/assets/document/pdf/Otomotiv-SektorelGorunum-Ocak2018.pdf. Erişim tarihi: 17 Ocak 2019.

Başdeğirmen, A. ve Iş1ldak B. (2018). Ulaştırma sektöründe faaliyet gösteren işletmelerin performanslarının gri ilişkisel analiz ile değerlendirilmesi. Süleyman Demirel Üniversitesi İktisadi ve İdari Bilimler Fakültesi Dergisi, 23(2), 563-577.

Başdeğirmen, A. ve Tunca, M. Z. (2017). Lojistik sektöründe faaliyet gösteren işletmelerin finansal performanslarının gri ilişkisel analiz ile değerlendirilmesi. Süleyman Demirel Üniversitesi İktisadi ve İdari Bilimler Fakültesi Dergisi, 22(2), 327-340.

Can, G. F., Atalay, K. D. ve Eraslan, E. (2017). Tabletlerin kullanılabilirlik ölçütlerine göre çok kriterli karar verme yaklaşımıyla değerlendirilmesi. Mühendislik Bilimleri ve Tasarım Dergisi, 5, 81-88.

Çakir, S. ve Perçin, S. (2013). Çok kriterli karar verme teknikleriyle lojistik firmalarinda performans ölçümü. Ege Akademik Bakış, 13(4), 449.

Çakır, E. ve Sezen Akar, G. (2017). Bütünleşik SWARA-TOPSIS yöntemi ile makine seçimi: Bir üretim işletmesinde uygulama. International Journal of Academic Value Studies (Javstudies), 3(13), 206-216.

Das, M. C., Sarkar, B. ve Ray, S. (2012). A framework to measure relative performance of Indian technical institutions using integrated fuzzy AHP and COPRAS methodology. Socio-Economic Planning Sciences, 46(3), 230-241.

Esbouei, S. K. ve Ghadikolaei, A. S. (2013). Applying FAHP and COPRAS methods for evaluating financial performance, International Journal of Management, IT and Engineering, Say1: 3(11), 10-22. 
Ginevičius, R. ve Podviezko, A. (2013). The evaluation of financial stability and soundness of Lithuanian banks. Economic research-Ekonomska istraživanja, 26(2), 191-208.

Iş1k, A. T. ve Adalı, E. A. (2016). A new integrated decision making approach based on SWARA and OCRA methods for the hotel selection problem. International Journal of Advanced Operations Management, 8(2), 140-151.

Kaplanoğlu, E. (2018). ARAS ve COPRAS yöntemleriyle nakit akışına dayalı performans ölçümü: BİST kimya, petrol, kauçuk ve plastik ürünler sektöründe bir uygulama. Muhasebe ve Vergi Uygulamalari Dergisi (Muvu)/Journal Of Accounting \& Taxation Studies (JATS), 11(2).

Karabašević, D., Stanujkić, D. ve Urošević, S. (2015). The MCDM model for personnel selection based on SWARA and ARAS methods. Management: Journal of Sustainable Business and Management Solutions In Emerging Economies, 20 (77): 43-52.

Karabašević, D., Stanujkić, D., Urošević, S. ve Maksimovic, M. (2015). Selection of candidates in the mining industry based on the application of the SWARA and the MULTIMOORA methods. Acta Montanistica Slovaca, 20(2): 116-124.

Karabasevic, D., Zavadskas, E. K., Turskis, Z. ve Stanujkic, D. (2016). The framework for the selection of personnel based on the SWARA and ARAS methods under uncertainties. Informatica, 27(1), 49-65.

Keršulienė, V. ve Turskis, Z. (2011). Integrated fuzzy multiple criteria decision making model for architect selection. Technological and Economic Development of Economy, 17(4), 645-666.

Keršuliene, V., Zavadskas, E. K. ve Turskis, Z. (2010). Selection of rational dispute resolution method by applying new step-wise weight assessment ratio analysis (SWARA). Journal of Business Economics and Management, 11(2), 243-258.

Mulliner, E., Smallbone, K. ve Maliene, V. (2013). An assessment of sustainable housing affordability using a multiple criteria decision making method. Omega, 41(2), 270-279.

Ömürbek, N. ve Akçakaya, E. D. U. (2018). Forbes 2000 listesinde yer alan havacılık sektöründeki şirketlerin entropi, MAUT, COPRAS ve SAW yöntemleri ile analizi. Süleyman Demirel Üniversitesi İ̈BF Dergisi, 23(1), 257-278.

Ömürbek, N. ve Eren, H. (2016). Promethee, MOORA ve COPRAS yöntemleri ile oran analizi sonuçlarının değerlendirilmesi: Bir uygulama-Evaluation of the results of the rate analysis with Promethee, MOORA and COPRAS 
methods: An application. Mehmet Akif Ersoy Üniversitesi Sosyal Bilimler Enstitüsü Dergisi, 8(16), 174-187.

Ömürbek, V., Aksoy, E. ve Akçakanat, Ö. (2017). Bankaların sürdürülebilirlik Performanslarının ARAS, MOOSRA ve COPRAS Yöntemleri ile Değerlendirilmesi. Süleyman Demirel Üniversitesi Vizyoner Dergisi, 8(19), 14-32.

Özbek, A. (2017). Çok kriterli karar verme yöntemleri ve Excel ile problem çözümü. Ankara: Seçkin Yayıncılık.

Özbek, A. (2018). Fortune 500 listesinde yer alan lojistik firmaların değerlendirilmesi. Afyon Kocatepe Üniversitesi İktisadi ve İdari Bilimler Fakültesi Dergisi, 20(1), 13-26.

Özbek, A. ve Demirkol, İ. (2018). Lojistik sektöründe faaliyet gösteren işletmelerin SWARA ve GİA yöntemleri ile analizi. Kırıkkale Üniversitesi Sosyal Bilimler Dergisi, 8(1), 71-86.

Rabbani, A., Zamani, M., Yazdani-Chamzini, A. ve Zavadskas, E. K. (2014). Proposing a new integrated model based on sustainability balanced scorecard (SBSC) and MCDM approaches by using linguistic variables for the performance evaluation of oil producing companies. Expert Systems with Applications, 41(16), 7316-7327.

Safaei Ghadikolaei, A., Khalili Esbouei, S. ve Antucheviciene, J. (2014). Applying fuzzy MCDM for financial performance evaluation of Iranian companies. Technological and Economic Development of Economy, 20(2), 274-291.

Stanujkic, D., Djordjevic, B. ve Karabasevic, D. (2015). Selection of candidates in the process of recruitment and selection of personnel based on the SWARA and ARAS methods. Quaestus Multidisciplinary Research Journal, 7, 53-62.

Stanujkicć, D., Đorđević, B. ve Đorđević, M. (2013). Comparative analysis of some prominent MCDM methods: A case of ranking Serbian banks. Serbian Journal of Management, 8(2), 213-241.

Stanujkic, D., Karabasevic, D. ve Zavadskas, E. K. (2015). A framework for the selection of a packaging design based on the SWARA method. Inzinerine Ekonomika-Engineering Economics, 26(2), 181-187.

Uygurtürk, H. ve Soylu, N. (2016). Girişim sermayesi yatırım ortaklıklarının likidite ve karlılık performanslarının COPRAS yöntemi ile analizi. Hitit Üniversitesi Sosyal Bilimler Enstitüsü Dergisi, 9(2), 637-650.

Yavuz, Ö. G. H. ve Öztel, A. (2017). Entropi tabanlı COPRAS yöntemı ile ölçek bazında fınansal performans analizi: Bilgi ve iletişim sektöründe bir uygulama, (1. IERFM) Uluslararası Ekonomi Araştırmaları ve Finansal 
Piyasalar Kongresi, 1. IERFM Tam Metin Bildiriler Kitabl, Detay Yayıncılik, 122-141.

Yazdani, M., Hashemkhani Zolfani, S. ve Zavadskas, E. (2016). New integration of MCDM methods and QFD in the selection of green suppliers. Journal of Business Economics and Management, 17(6), 1097-1113.

Yurdakul, M. ve İç, Y. T. (2003). Türk otomotiv firmalarının performans ölçümü ve analizine yönelik TOPSIS yöntemini kullanan bir örnek çalışma. Gazi Üniversitesi Mühendislik-Mimarlık Fakültesi Dergisi, 18(1).

Zolfani, S. H. ve Banihashemi, S. S. A. (2014). Personnel selection based on a novel model of game theory and MCDM approaches. Proc. of 8th International Scientific Conference Business and Management, 15-16.

Zolfani, S. H., Pourhossein, M., Yazdani, M. ve Zavadskas, E. K. (2018). Evaluating construction projects of hotels based on environmental sustainability with MCDM framework. Alexandria Engineering Journal, 57(1), 357-365.

Zolfani, S. H., Zavadskas, E. K. ve Turskis, Z. (2013). Design of products with both international and local perspectives based on Yin-Yang balance theory and SWARA method.Economic research-Ekonomska istraživanja, 26(2), 153-166. 


\section{Evaluation of Fortune 500 Listed Automotive Companies by SWARA Supported COPRAS Method}

\section{Extended Abstract}

\section{Introduction}

The automotive sector is one of the locomotive sectors of our economy. High value-added rates, closely following the structure of technological developments, attractive property for investors and positive impact on foreign trade figures pose an important place in Turkey's economy. The automotive industry contributes to the technological development momentum in iron, steel, fuel, energy, chemistry, electronics, software, and textile sectors. It also plays a major role in the creation of business volume and employment for many service sectors, such as tourism, maintenance, insurance, and distributorship. In this context, all kinds of changes in the sector are closely related to the whole economy.

Multi-criteria decision-making methods are used to select the best among the alternatives with different characteristics according to multiple criteria or to rank these alternatives according to their performance according to the determined target. The performance evaluation process in enterprises is a decision-making problem based on many criteria and multi-criteria decisionmaking techniques are suitable for use in this field.

The purpose of this study is to realize the performance analysis of the automotive companies in Turkey Fortune 500 list which are located in the first 10 rows of 2017 as net sales. For this purpose, SWARA supported COPRAS method is preferred to use.

Achieving information about the current performances of enterprises in the sector is important for entrepreneurs, investors and company managers both in determining their position in the sector and in developing competitive strategies for the future. The study is thought to contribute to this context.

\section{Method}

The firms that are subject to this analysis are grouped in the sub-sectors of the manufacturing and maintenance of vehicles and equipment and the sales and service of motor vehicles.

The criteria taken into account in the performance analysis of automotive companies are as follows: net sales, net sales change, profit before interest and tax, profit change before interest and tax, total assets, equity, exports and number of employees.

The SWARA method is used to calculate the weights of the criteria used in the analysis. In order to compare the decision alternatives and perform the performance rankings, the COPRAS method which is one of the new multi-criteria decision-making methods is preferred.

\section{Results and Discussion}

In this study, the ranking of the companies operating in the automotive sector, which is in the FORTUNE 500 list and constitutes the top 10 in terms of net sales amount in 2017, is performed according to performance. The criteria used in the evaluation are net sales, net sales change, profit before interest and tax, profit change before interest and tax, total assets, equity, exports and number of employees. In this study, SWARA and COPRAS, which are multi-criteria decisionmaking methods, are used integrally. The SWARA method is preferred in determining the weights of the criteria included in the analysis, and the performance ranking of the companies is reached by the COPRAS method based on this criterion weights. The most important evaluation criterion is found in net sales (K1). Among the other criteria, the equity and the profit before tax and interest criteria are found to be highly effective in terms of performance evaluation. The company which 
has the best performance in the relevant period is Ford Otomotiv Sanayi A.Ş. (F1). The second company is Doğuş Otomotiv Servis ve Ticaret A.Ş. (F2) and the third one is Otokoç Otomotiv Ticaret ve Sanayi A.Ş. (F3). This ranking is consistent with the FORTUNE 500 list ranking. Avek Otomotiv Servis Sanayi ve Ticaret A.S. (F7) is the company that has the lowest performance in the period analyzed.

\section{Conclusion}

The main motivation of the study is to guide the business stakeholders in terms of interpreting the performance of the automotive sector and making appropriate decisions. As a result of the performance ranking performed, the top-ranking firms are advisable for investors. Recent firms may be advised to identify their strengths and weaknesses based on their successful competitors and to reform their competitive strategies by focusing on net sales, equity and pre-tax profit criteria.

It should be taken into consideration that there may be a change in the performance ranking of the firms within the scope of the assessment if changes in the criteria based on the application are made or a different period is taken into consideration. Moreover, the use of multi-criteria decisionmaking techniques other than SWARA and COPRAS methods may bring differences in the results of the analysis. In the following studies, the similarity of criteria can be compared by performing performance measurement applications covering different sectors or the rankings obtained can be compared with the usage of different multi-criteria decision-making techniques. 